\title{
Glutamatergic Synapse Formation is Promoted by $\alpha 7$-Containing Nicotinic Acetylcholine Receptors
}

\author{
Adrian F. Lozada, ${ }^{1}$ Xulong Wang, ${ }^{1}$ Natalia V. Gounko, ${ }^{1,2}$ Kerri A. Massey, ${ }^{1,3}$ Jingjing Duan, ${ }^{1,4}$ Zhaoping Liu, ${ }^{1,5}$ \\ and Darwin K. Berg ${ }^{1}$ \\ ${ }^{1}$ Neurobiology Section, Division of Biological Sciences, University of California, San Diego, La Jolla, California 92093-0357, ${ }^{2}$ Scripps Research Institute, La \\ Jolla, California 92037, ${ }^{3}$ Amgen, Inc., Thousand Oaks, California 91360, ${ }^{4}$ Department of Anatomy and Neurobiology, Zhongshan School of Medicine, Sun \\ Yat-Sen University, Guangzhou 510080, China, and ${ }^{5}$ IntelliCyt Corporation, Albuquerque, New Mexico 87113.
}

Glutamate is the primary excitatory transmitter in adult brain, acting through synapses on dendritic spines and shafts. Early in development, however, when glutamatergic synapses are only beginning to form, nicotinic cholinergic excitation is already widespread; it is mediated by acetylcholine activating nicotinic acetylcholine receptors (nAChRs) that generate waves of activity across brain regions. A major class of nAChRs contributing at this time is a species containing $\alpha 7$ subunits ( $\alpha 7$-nAChRs). These receptors are highly permeable to calcium, influence a variety of calcium-dependent events, and are diversely distributed throughout the developing CNS. Here we show that $\alpha 7$-nAChRs unexpectedly promote formation of glutamatergic synapses during development. The dependence on $\alpha 7$-nAChRs becomes clear when comparing wild-type (WT) mice with mice constitutively lacking the $\alpha 7$-nAChR gene. Ultrastructural analysis, immunostaining, and patch-clamp recording all reveal synaptic deficits when $\alpha 7$-nAChR input is absent. Similarly, nicotinic activation of $\alpha 7$-nAChRs in WT organotypic culture, as well as cell culture, increases the number of glutamatergic synapses. RNA interference demonstrates that the $\alpha 7$-nAChRs must be expressed in the neuron being innervated for normal innervation to occur. Moreover, the deficits persist throughout the developmental period of major de novo synapse formation and are still fully apparent in the adult. GABAergic synapses, in contrast, are undiminished in number under such conditions. As a result, mice lacking $\alpha 7$-nAChRs have an altered balance in the excitatory/inhibitory input they receive. This ratio represents a fundamental feature of neural networks and shows for the first time that endogenous nicotinic cholinergic signaling plays a key role in network construction.

\section{Introduction}

Glutamatergic pathways comprise the principal excitatory networks in the CNS, using a combination of synapses on dendritic spines and shafts to embed neurons in circuits (Fiala et al., 1998; Sheng and Hoogenraad, 2007). How synaptogenesis is coordinated across neuronal populations to form networks remains poorly understood. An intriguing possibility is that nicotinic cholinergic signaling plays a key role. Nicotinic acetylcholine receptors (nAChRs) reach their highest relative levels early in development (Zhang et al., 1998; Adams et al., 2002) when glutamatergic synapses are initially forming (Fiala et al., 1998; Hennou et al., 2002). Activation of nAChRs by the neurotransmitter acetylcholine produces spontaneous waves of excitation throughout much of the nervous system at this time (Bansal et al.,

Received Dec. 15, 2011; revised April 9, 2012; accepted April 17, 2012.

Author contributions: A.F.L., X.W., N.V.G., K.A.M., J.D., Z.L., and D.K.B. designed research; A.F.L., X.W., N.V.G., K.A.M., J.D., and Z.L. performed research; A.F.L., X.W., N.V.G., K.A.M., J.D., Z.L., and D.K.B. analyzed data; A.F.L., X.W., and D.K.B. wrote the paper.

Grant support was provided by the US National Institutes of Health (NS012601, NS034569, and DA237482) and the Tobacco-Related Disease Research Program (17FT-0053 and 19XT-0072).We thank Uwe Maskos and Andrew W. Halff for the $\beta 2$ - and $\alpha 7$-RNAi constructs, respectively; Xiao-Yun Wang and Jeff Schoellerman for expert technical assistance; and Gentry Patrick and Stevan Djakovic for stocks of sindbis-GFP.

The authors declare no competing financial interests.

Correspondence should be addressed to Darwin K. Berg, Neurobiology Section, Division of Biology, 0357, University of California, San Diego, 9500 Gilman Drive, La Jolla, CA 92093-0357. E-mail: dberg@ucsd.edu.

DOI:10.1523/JNEUROSCI.6246-11.2012

Copyright $\odot 2012$ the authors $\quad 0270-6474 / 12 / 327651-11 \$ 15.00 / 0$
2000; Hanson and Landmesser, 2003; Le Magueresse et al., 2006). Early nicotinic signaling is known to influence specific aspects of local circuit formation and pathfinding (Grubb et al., 2003; Hanson and Landmesser, 2003, 2006; Myers et al., 2005).

A major nAChR subtype in brain is the $\alpha 7$-containing homopentamer $(\alpha 7-\mathrm{nAChR})$, which has a high relative permeability to calcium (Bertrand et al., 1993; Séguéla et al., 1993). The location of $\alpha 7$-nAChRs (Jacob and Berg,1983; Fabian-Fine et al., 2001) and their calcium permeability enable the receptors to influence diverse events, ranging from modulation of transmitter release and synaptic plasticity (McGehee et al., 1995; Gray et al., 1996; Alkondon and Albuquerque, 2001; Dickinson et al., 2008; Zhong et al., 2008; Albuquerque et al., 2009; Gu and Yakel, 2011) to control of gene expression (Chang and Berg, 2001; Hu et al., 2002; Dajas-Bailador and Wonnacott, 2004). The $\alpha 7$-nAChRs also help determine when GABAergic transmission converts from excitation to inhibition during development (Liu et al., 2006), and they help drive survival and maturation of adultborn neurons in the hippocampus (Campbell et al., 2010). Not surprisingly, $\alpha 7$-nAChRs have been implicated in a variety of neurological functions and disorders (Freedman et al., 2001; Liu et al., 2001; Picciotto and Zoli, 2002; Grassi et al., 2003; Harrison and Weinberger, 2005; Hoyle et al., 2006; Levin et al., 2009).

Here we show that early endogenous nicotinic activity through $\alpha 7$-nAChRs is a major determinant promoting the de- 
velopment of glutamatergic pathways formed in the brain. Transgenic mice lacking $\alpha 7$-nAChRs ( $\alpha 7$ knock-outs; $\alpha 7 \mathrm{KOs}$ ) acquire fewer glutamatergic synapses during early postnatal life. Activation of $\alpha 7$-nAChRs by chronic exposure to nicotine in culture increases the number of functional glutamatergic synapses. Receptor knockdown by RNA interference (RNAi) in vivo demonstrates that $\alpha 7-\mathrm{nAChRs}$ must be expressed by the postsynaptic neuron to receive proper glutamatergic innervation. GABAergic synapses remain unchanged both in culture and in vivo; this causes a shift in glutamatergic/GABAergic input to $\alpha 7 \mathrm{KO}$ neurons. The changes produced during development by disrupted nicotinic cholinergic input represent substantial network aberrations and may account for lasting behavioral deficits reported for mice lacking the receptors (Fernandes et al., 2006; Hoyle et al., 2006; Young et al., 2007; Levin et al., 2009). This is an unexpected and important role for endogenous nicotinic cholinergic signaling.

\section{Materials and Methods}

Viral injections. High-titer lentiviral stocks containing short-hairpin RNAs representing RNAi or scrambled control sequences were obtained from the Viral Vector Core (Salk Institute). For lentiviral injections, P1-P2 mice of either sex were anesthetized and then stabilized in a custom clay mold before receiving $70 \mathrm{nl}$ of high-titer lentiviral stock intracranially at each of five sites using a Nanoject (Drummond Scientific ) and beveled glass injection pipette (Adesnik et al., 2008). Animals were allowed to recover and returned to the dam immediately after injection; $10-11 \mathrm{~d}$ later they were perfusion fixed with $4 \%$ paraformaldehyde (PFA). Analyses were performed blind to genotype and viral construct.

Perfusion-fixed tissue slices. Perfusion-fixed tissue slices were obtained by anesthetizing animals of either sex with ketamine/xylazine, transcardially perfusing with $4 \% \mathrm{PFA}$, and postfixing for $1-2 \mathrm{~h}$. Brains were cryoprotected in $0.1 \mathrm{M}$ phosphate buffer, $\mathrm{pH} 7.4$, containing $25 \%$ sucrose and sectioned at $40 \mu \mathrm{m}$ with a Leica cryostat. The $\alpha 7 \mathrm{KO}$ mouse C57BL/6J line was purchased from Jackson Laboratories. A mouse line lacking the $\beta 2$-nAChR gene $(\beta 2 \mathrm{KO})$ was provided by Marla Feller (University of California, Berkeley) and crossed with the $\alpha 7 \mathrm{KO}$ line to generate double knock-out mice (dKO). In all cases, results were based on pups from $\geq 2$ litters per genotype.

Mouse hippocampal slice cultures. Fresh brain tissue for slice cultures was obtained by rapidly excising $\mathrm{P} 0-\mathrm{P} 1$ mouse brains into icecold artificial CSF (ACSF) saturated with 95\% $\mathrm{O}_{2} / 5 \% \quad \mathrm{CO}_{2}$, containing (in mM): $\mathrm{NaCl} 119, \mathrm{KCl} 2.5, \mathrm{CaCl}_{2} 2.5, \mathrm{MgSO}_{4} 1.3$, $\mathrm{NaH}_{2} \mathrm{PO}_{4}$ 1.0, $\mathrm{NaHCO}_{3}$ 26.2, and glucose 11. Vibratome sections $(150-200 \mu \mathrm{m})$ were plated onto Millicell inserts (Millipore) in culture medium (Neurobasal plus $10 \%$ horse serum), and incubated at $37^{\circ} \mathrm{C}$ in a humidified chamber with $5 \% \mathrm{CO}_{2}$ for $4-7 \mathrm{~d}$ (Stoppini et al.,1991).

D

E
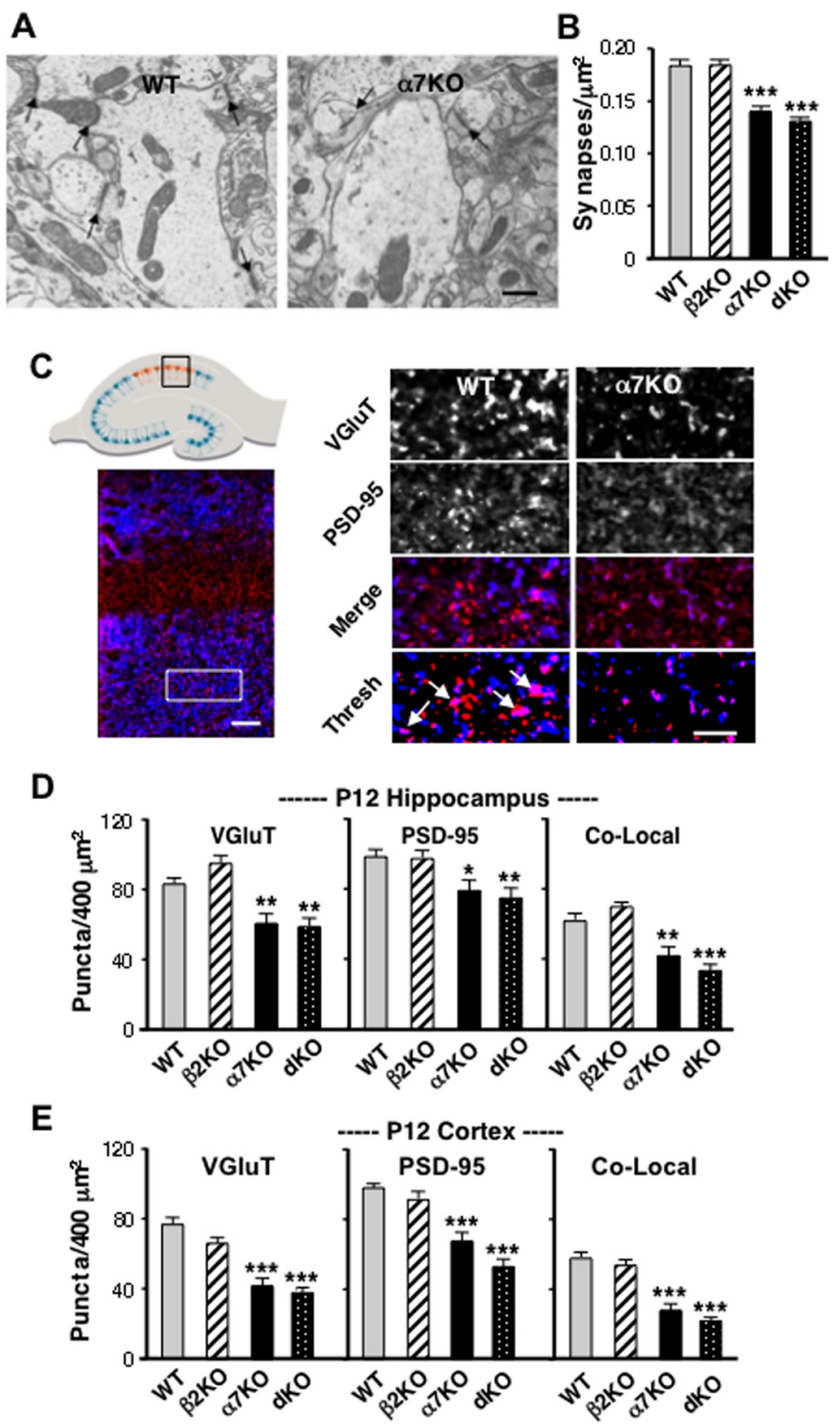

Figure 1. Decrement in the number of glutamatergic synapses in $\alpha 7 \mathrm{KO}$ mice. $A$, EMs showing synapses (arrows) in regions containing apical dendrites of CA1 pyramidal neurons in P8 hippocampal slices from WT and $\alpha 7 \mathrm{KO}$ mice. Scale bar, $0.5 \mu \mathrm{m}$. $\boldsymbol{B}$, Number of ultrastructurally identified synapses/ $\mu \mathrm{m}^{2}$ ( $\geq 150$ images from 3 animals/genotype). C, Pictures showing a diagram of the hippocampus (upper left) with a box indicating the CA1 region used for imaging and low-magnification image of the CA1 region (lower left) with a box indicating the general area used for higher power images (right) of CA1 apical dendrite regions in P12 WT and $\alpha 7 \mathrm{KO}$ mice. Slices were immunostained for glutamatergic synapses using the markers VGluT (blue), PSD-95 (red), and the images were merged (Merge) and thresholded (Thresh) to remove pixels of below-threshold intensity (arrows indicate examples of colocalization). Scale bars: $20 \mu \mathrm{m}$, left; $5 \mu \mathrm{m}$, right. D, Number of VGluT, PSD-95, and colocalized puncta/400 $\mu \mathrm{m}^{2}$ for the indicated genotype in the CA1. $E$, Number of VGluT, PSD-95, and colocalized puncta $/ 400 \mu \mathrm{m}^{2}$ at P12 on neurons in layer $5 / 6$ of the cortex (3- 4 cells/animal; $5-8$ animals/genotype from $\geq 2$ litters).

Rat hippocampal dissociated cell cultures. Rat dissociated hippocampal cell cultures were prepared from embryonic day 18 embryos of either sex and grown 10-21 d as described previously (Zhang and Berg, 2007).

Immunohistochemistry. Fixed $40-\mu \mathrm{m}$-thick brain sections were dried at room temperature and washed three times in PBS, pH 7.4, with $0.3 \%$ Triton X-100 (PBST). Sections (and slices from organotypic culture) were incubated overnight at $4^{\circ} \mathrm{C}$ in PBST with $10 \%$ normal donkey serum containing rabbit anti-PSD-95 (1:500; Life Technologies), or rabbit anti-phospho GluR1 (glutamate receptor 1; 1:500, Millipore) and guinea 
pig anti-vesicular glutamate transporter (anti-VGluT; 1:2500 for VGluT1; Bioscience Research Reagents), or guinea pig anti-vesicular GABA transporter (anti-VGAT; 1:250, Synaptic Systems) and rabbit anti-GABA $A_{A} \alpha 1$ receptor (1:500; Alomone Labs). Sections were then washed three times with PBST and incubated for $2 \mathrm{~h}$ with PBST containing secondary CF dye-labeled antibodies (1:500, goat anti-guinea pig CF633 and donkey anti-rabbit CF555; Biotium). Slides were mounted with medium (Vectashield; Vector Laboratories) and imaged using a Leica TCS SP5 confocal microscope (Leica Microsystems). Nonspecific immunostaining was assessed by substituting nonimmune IgG for the primary antibody and found to be negligible.

Surface staining of live cells in culture was achieved by incubating with rabbit anti-GluR1 antibody (1:20; Calbiochem) or rabbit anti-GABA $\alpha$-1 antibody (1:50; Alomone Labs) in media on ice. Cells were then washed five times with ice-cold ACSF saturated with $95 \% \mathrm{O}_{2} / 5 \% \mathrm{CO}_{2}$ and fixed with $2 \%$ PFA for $10 \mathrm{~min}$. Fixed cells were then incubated with mouse anti-PSD 95 (1:1000; Affinity BioReagents) or mouse antiGAD-65 monoclonal antibody (mAb; 1:20, Developmental Studies Hybridoma Bank) for costaining, and with donkey anti-rabbit Cy3 and anti-mouse FITC or Cy5 as secondary antibodies (all at 1:500; Jackson ImmunoResearch Laboratories) for $2 \mathrm{~h}$ at room temperature. Another primary antibody used on fixed cells was rabbit anti-VGluT (1:1000; Synaptic Systems).

Fluorescence imaging. Fluorescence images were obtained with a Leica TCS SP5 confocal microscope using ImageJ for analysis of brain slices. For cells in culture, images were obtained with a Zeiss Axiovert S100 TV microscope and Slidebook software (Intelligent Imaging Innovations) applied to three vertical stacks of contiguous optical sections. To visualize dendrites in hippocampal and cortical slices from perfusion-fixed animals, green fluorescent protein (GFP) was introduced in vivo via lentiviral constructs. Results were equivalent in the two cases and therefore combined. Brain sections (36-45 per animal) and hippocampal slices from organotypic culture were stained independently for presynaptic and postsynaptic markers, and confocal scans were performed in the CA1 region of the hippocampus or layer 5/6 in the visual cortex. Imaging parameters were identical for all WT and transgenic animals, as well as for slice and cell cultures exposed to drugs. WTs (or controls for viral construct and drug exposure where appropriate) were always included in all experiments to normalize for expected variations in antibody staining intensity performed on different days. To minimize antibody penetration problems, only three merged optical sections localized close to the tissue surface were used per slice (9-15 images per animal). The three merged optical sections were analyzed using the ImageJ puncta analyzer program. Thresholds were set at $3 \mathrm{SDs}$ above the mean staining intensity of six nearby regions in the same visual field. Thresholded images present a fixed intensity for all pixels above threshold after having removed all of those below. Labeled puncta were defined as areas containing at least four contiguous pixels after thresholding. Colocalization of puncta (e.g., VGluT and PSD-95) required that they have at least one pixel in common as revealed by ImageJ applied to the three merged optical sections or as revealed by Slidebook software in the case of cell cultures. Quantifications were performed blind to condition.

Electron microscopy. Hippocampal slices from P8 mice of either sex were obtained by perfusing the animals transcardially with $4 \%$ PFA and $0.2 \%$ picric acid in $0.1 \mathrm{~m}$ sodium cacodylate buffer, $\mathrm{pH} 7.6$, and then removing the brains, storing them in the same solution overnight at $4^{\circ} \mathrm{C}$, and sectioning at $100 \mu \mathrm{m}$ in the sagittal plane with a Vibratome. Hippocampal slices from organotypic cultures ( $\mathrm{P} 4$ in culture $4 \mathrm{~d}$ ) were obtained by fixing the cultures in $4 \%$ PFA and $0.2 \%$ picric acid in $\mathrm{CB}$ overnight at $4^{\circ} \mathrm{C}$, washing in $\mathrm{CB}$, and fixing an additional $15 \mathrm{~min}$ with $0.2 \%$ glutaraldehyde in CB. The fixed slices were incubated in $1 \% \mathrm{OsO}_{4}$ and $1.5 \%$ potassium hexacyanoferrate in cacodylate buffer for $15 \mathrm{~min}$, then dehydrated in a graded series of ethanol concentrations, and embedded in Epon. Semithin sections stained with toluidine blue were used for orientation. Ultrathin sections of the CA1 region were counterstained with uranyl acetate and lead citrate and examined with a JEM-1200EXII electron microscope operated at $80 \mathrm{kV}$ and Tietz Video Image Processing Systems $4 \mathrm{~K}$ with a $4 \mathrm{~K}$ F415 CCD camera. Alternatively, negatives were digitized with a CanonScan D 1230 U scanner at 1200 dpi. For drug
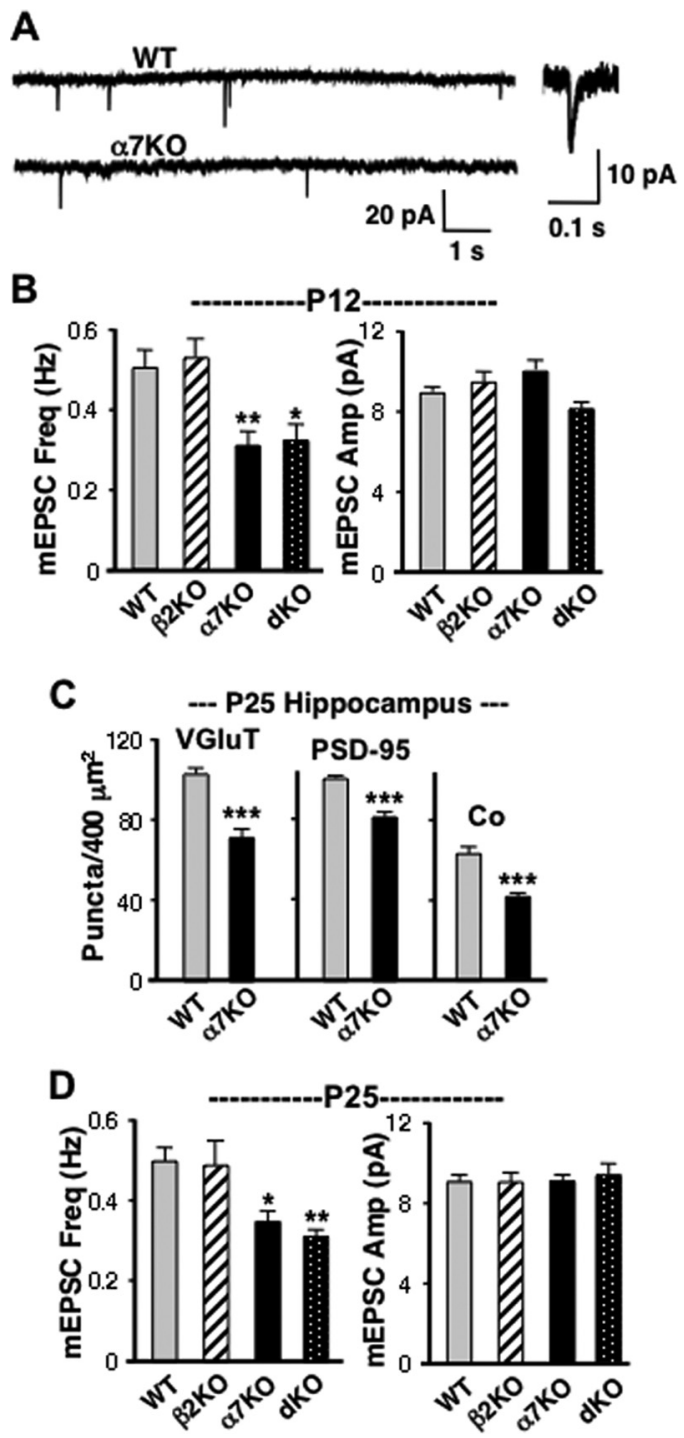

Figure 2. Electrophysiological analysis showing reduced mEPSC frequency in $\alpha 7 \mathrm{KO}$ mice compared with WTs. $\boldsymbol{A}$, Patch-clamp recordings of spontaneous mEPSCs in CA1 pyramidal neurons from P12 WT and $\alpha 7 \mathrm{~K} 0$ acute slices in TTX and gabazine. Inset, WT mEPSC with expanded time scale. $\boldsymbol{B}$, Quantification of mEPSC frequency (left) and amplitude (right) at P12. C, Number of VGluT, PSD-95, and colocalized puncta/400 $\mu \mathrm{m}^{2}$ in the CA1 region of P25 WTs and $\alpha 7 \mathrm{KO}$ s analyzed as in Figure 1.D, Quantification of mEPSC frequency (left) and amplitude (right) at P25 for the indicated genotypes. Loss of the $\alpha 7-n A C h R$ gene product, but not the $\beta 2-n A C h R$ gene product, correlates with reduced $m E P S C$ frequency with no change in mEPSC amplitude, a result consistent with $\alpha 7 \mathrm{~K} 0$ s having fewer functional glutamatergic synapses ( $\geq 50$ events/cell, 11-19 cells from 4-7 animals/genotype).

treatments, slices from a common pool were divided among conditions. In all cases, separate tissue blocks were prepared for each slice (2-6 blocks per condition), and a single section from each block was used for synapse quantification so that possible overlap between sections would be avoided. Synapses were identified by ultrastructural specializations including alignment of presynaptic and postsynaptic membranes, presynaptic and postsynaptic thickenings, and clusters of synaptic vesicles. Counts were performed blind to condition (65-207 images per condition).

Electrophysiology. Whole-cell patch-clamp recording was performed on CA1 pyramidal neurons in acute hippocampal P12 and P25 slices as described previously (Zhang and Berg, 2007; Campbell et al., 2010). Before recording from slices ( $300 \mu \mathrm{m}$ thick), a 30 min recovery was allowed at $37.5^{\circ} \mathrm{C}$, followed by $30 \mathrm{~min}$ at room temperature. The bath contained (in mM): $119 \mathrm{NaCl}, 2.5 \mathrm{KCl}, 2.5 \mathrm{CaCl}_{2}, 1.3 \mathrm{MgSO}_{4}, 1.0 \mathrm{NaH}_{2} \mathrm{PO}_{4}, 26.2$ 
$\mathrm{NaHCO}_{3}$, and 11 glucose, and was saturated with $95 \% \mathrm{O}_{2} / 5 \% \mathrm{CO}_{2}$ (to yield $\mathrm{pH}$ 7.4). Patch pipettes $(4-5 \mathrm{M} \Omega$ ) were filled with (in $\mathrm{mM}$ ): 130 Cs-methylsulfonate, $3 \mathrm{CsCl}, 10$ HEPES, 1 EGTA, $10 \mathrm{Na}_{2}$-phosphocreatine, and $2 \mathrm{MgATP}$ (adjusted to pH 7.4). For recordings in cell culture (Conroy et al., 2007) the bath contained (in mM): $150 \mathrm{NaCl}, 5 \mathrm{KCl}, 2 \mathrm{CaCl}_{2}, 1 \mathrm{MgCl}_{2}, 10$ HEPES, and 10 glucose ( $\mathrm{pH} 7.4$, with $\mathrm{NaOH})$ at room temperature. The patch pipettes (3-4 $\mathrm{M} \Omega$ ) were filled with (in $\mathrm{mm}$ ): 122.5 gluconic acid, $122.5 \mathrm{CsOH}, 10 \mathrm{CsCl}, 5 \mathrm{NaCl}, 1.5 \mathrm{MgCl}_{2}$, 5 HEPES, 1 EGTA, $10 \mathrm{Na}_{2}$-phosphocreatine, 3 MgATP, and 0.3 NaGTP (pH 7.25, with $\mathrm{CsOH})$, and the recordings were made from neurons in 10- to 13-d-old cultures. Pipette capacitance was minimized in all recordings; series resistance was $<25 \mathrm{M} \Omega$. Data were acquired at $10 \mathrm{kHz}$ and filtered at $1 \mathrm{kHz}$. When recording spontaneous miniature EPSCs (mEPSCs), $1 \mu \mathrm{M}$ tetrodotoxin (TTX) was used to block action potentials and $20 \mu \mathrm{M}$ gabazine to block $\mathrm{GABA}_{\mathrm{A}}$ receptor-mediated postsynaptic currents (PSCs). No difference was found in $\mathrm{mEPSC}$ frequencies recorded from WT littermates versus C57BL/6 $\mathrm{J}$ WTs purchased from Jackson Laboratories $(0.49 \pm 0.08$ vs $0.51 \pm 0.04 \mathrm{~Hz}$, respectively; $n=9,10$ cells from 3, 4 animals), so values for the two were combined. For evoked PSCs, a bipolar stimulating electrode was positioned over the Schaffer collaterals $\sim 400 \mu \mathrm{m}$ from the patch-clamped neuron. Blockade of AMPA and NMDA receptors with aminophosphonovalerate (APV) and 2,3-dihydroxy-6-nitro-y-sulfonyl-benzo[f]quinoxaline (NBQX), respectively, confirmed that all of the evoked PSC detected at $-70 \mathrm{mV}$ was due to glutamatergic transmission under these conditions (Atallah and Scanziani, 2009). Blockade of $\mathrm{GABA}_{\mathrm{A}}$ receptors with gabazine confirmed that all of the evoked PSC detected at $0 \mathrm{mV}$ was due to GABAergic transmission. When needed, methyllycaconitine (MLA; $100 \mathrm{~nm}$ ) and dihydro- $\beta$-erythroidine (DH $\beta \mathrm{E} ; 10 \mu \mathrm{M})$

were used to block $\alpha 7$-nAChRs and $\beta 2$-containing heteromeric nAChRs $\left(\beta 2^{\star}\right.$-nAChRs), respectively. For mEPSCs, events were analyzed by Mini Analysis Program software (Synaptosoft). Evoked PSCs were analyzed with Clampfit 9.2.

RNAi constructs. The $\beta 2$-RNAi construct (generously provided by Uwe Maskos; Avale et al., 2008) targeting the mouse $\beta 2$-nAChR transcript was tested for effectiveness by using Lipofectamine 2000 (Life Technologies) to transfect HEK293T cells on glass coverslips with plasmids encoding $\alpha 4$-nAChR subunit from chicken, cyan fluorescent protein (CFP)-tagged $\beta 2$-nAChR subunit from mouse (Addgene plasmid 15106 , developed by H. Lester; Caltech), and GFP together with either $\beta 2$-RNAi or a scrambled version of the sequence ( $\beta 2$-Scr) as nonspecific control (1:1:3 transfection ratio). Two days after transfection, the cells were fixed with $2 \%$ PFA, permeabilized, mounted, and imaged with a Leica SP5 confocal microscope. Settings for laser power and wavelength range for detection were optimized using coverslip cultures not transfected with CFP to minimize cross talk between GFP and CFP channels. Images were taken of nearly confluent cells expressing GFP, blind to the CFP channel. CFP fluorescence was scored as the proportion of pixels above background, which was defined as the level of CFP fluorescence in cultures transfected with GFP but not CFP constructs. Transfection with the $\beta 2$-RNAi construct resulted in CFP levels that were $3 \pm 1 \%$ of those obtained with $\beta 2$-Scr, demonstrating the effectiveness of the $\beta 2$-RNAi in preventing production of $\beta 2^{\star}$-nAChRs, a second major class of nicotinic receptors in the CNS. The $\alpha 7$-RNAi construct, targeting the mouse $\alpha 7$ -
B

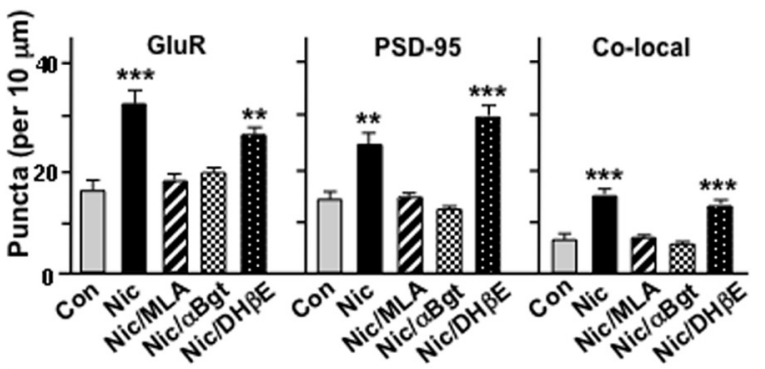

D

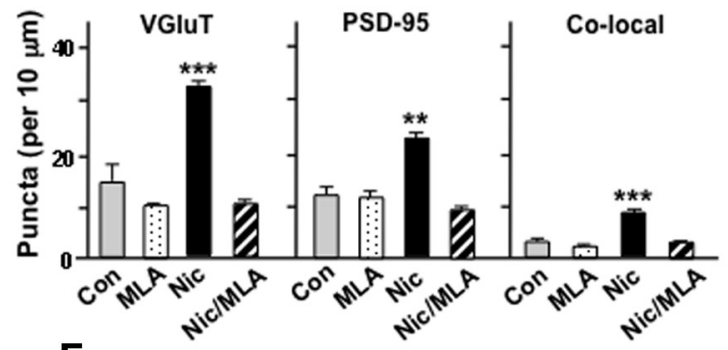

$\mathbf{F}$

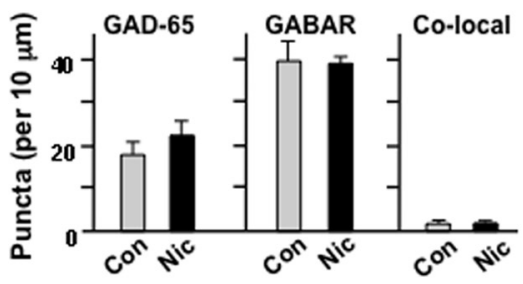

Figure 3. Nicotine in cell culture acts via $\alpha 7-n A C h R s$ to increase glutamatergic synaptic contacts. $A$, Control (Con) and nicotinetreated (Nic) cell cultures expressing GFP and surface stained for GluR1 receptors (red) and then intracellular PSD-95 (blue). Here changes in the numbers of GAD-65 and GABA receptor puncta (GABAR) or in their colocalization ( $n=3-4$ cultures; 5 a

nAChR transcript, was designed with a GenScript algorithm and shown to be homologous to both rat and mouse $\alpha 7$-mRNA sequences. The scrambled sequence ( $\alpha 7$-Scr) was obtained with a GenScript sequence scrambler and shown not to be homologous with any sequence in the rat and mouse genomes. The sequences were inserted into lentiviral vectors (FG12; Addgene plasmid 14884) under an H1 promoter along with GFP under a ubiquitin promoter and linked to their reverse complement by the loop sequence TCTCTTGAA to form an shRNA. Their compositions are 5'-GAGTGAGGTGATCTGCAGTGA-3' (BP 1356-1376) and 5'GAGAGTACGCTAAGATCCTAA- $3^{\prime}$ for the $\alpha 7$-RNAi and $\alpha 7$-Scr, respectively. The effectiveness of the lentiviral $\alpha 7$-RNAi construct was tested by infecting 16-d-old rat (E18 Sprague Dawley) or mouse (E18 C57B1/6) hippocampal $3.5 \mathrm{~cm}$ cultures (plated at 26,000 and 62,500 cells $/ \mathrm{cm}^{2}$, respectively) with $5 \mu \mathrm{l}$ virus stock $\left(1-5 \times 10^{7} \mathrm{IU} / \mathrm{ml}\right)$, and collecting the cells 1 week later. Solubilized $\alpha 7$-nAChRs were immunoprecipitated with mAb 319 (Sigma-Aldrich) and radiolabeled with I ${ }^{125}$. $\alpha$ Bungarotoxin ( $\mathrm{I}^{125}$ - $\alpha$ Bgt; PerkinElmer). Total protein was measured using the Bradford assay (Bio-Rad Protein Assay). Transfection with $\alpha 7$-RNAi reduced the amount of binding obtained to $7 \pm 1$ and $17 \pm$ $11 \%$ of that seen with $\alpha 7$-Scr in rat and mouse hippocampal cultures, respectively, demonstrating the $\alpha 7$-RNAi effectiveness. Off-target effects of $\beta 2$ - and $\alpha 7$-RNAi constructs were assessed by injecting the lentiviral constructs into the cognate $\mathrm{KO}$ mouse ( $\beta 2 \mathrm{KOs}$ and $\alpha 7 \mathrm{KOs}$ ) on P2 and assessing their effects either on spine number in the case of $\beta 2$-RNAi or VGluT and PSD-95 puncta in the case of $\alpha 7$-RNAi at P12. In each case the 
results were compared with those obtained with the corresponding scrambled control ( $\beta 2$-Scr or $\alpha 7$-Scr).

FM4-64 labeling. FM4-64 staining (Pyle et al., 1999) was performed by first labeling dendrites and spines with either DiI (Life Technologies) or GFP via a sindbis-viral construct (generous gift from Gentry Patrick, University of California, San Diego), rinsing cultures to remove nicotine, incubating $1 \mathrm{~h}$ in $50 \mathrm{~nm}$ MLA and $1 \mu \mathrm{M}$ DH $\beta E$ to block any residual nicotinic activity, and then incubating $60 \mathrm{~s}$ with $5 \mu \mathrm{M}$ FM4 $-64 \pm 50 \mathrm{mM}$ $\mathrm{KCl}$ before rinsing and imaging. Counts of FM4-64-labeled puncta along $10 \mu \mathrm{m}$ segments of dendrites were performed blind to condition.

Statistical analysis. Data represent means \pm SEMs. Unless otherwise indicated, statistical significance was assessed with Student's $t$ test for unpaired values and with one-way ANOVA followed by Bonferroni's post hoc test for multiple values. ${ }^{\star} p<0.05,{ }^{* *} p<0.01$; and ${ }^{* * *} p<0.001$.

\section{Results}

\section{Reduced numbers of glutamatergic synapses in mice} lacking $\alpha$-nAChRs

To determine whether endogenous nicotinic cholinergic signaling is needed for synapse formation in the developing brain, we first performed electron microscopic (EM) analysis comparing the abundance of synapses in WT and $\mathrm{KO}$ mice lacking one or more nAChR genes. Examining regions containing the apical dendrites of CA1 pyramidal neurons in $\mathrm{P} 8$ hippocampus revealed a significant deficit in $\alpha 7 \mathrm{KO}$ mice, compared either to WT mice or to $\beta 2 \mathrm{KO}$ mice (Fig. $1 A, B$ ). No further decrement was seen in $\mathrm{dKO}$ mice beyond that found in $\alpha 7 \mathrm{KO}$. This suggested that endogenous cholinergic signaling through $\alpha 7$-nAChRs, but not through $\beta 2^{\star}$-nAChRs, is important for synapse formation.

To determine whether the synaptic decrements represented a loss of glutamatergic synapses, we immunostained tissue slices for the presynaptic marker VGluT and the postsynaptic marker PSD-95. Colocalization of the two markers was used to identify glutamatergic synapses (Eroglu et al., 2009). Compared with WTs, both $\alpha 7 \mathrm{KOs}$ and $\mathrm{dKO}$ in the hippocampal CA1 region displayed clear deficits at P12 in their numbers of VGluT and PSD-95 puncta and in colocalization of the two (Fig. 1C,D). No deficits were seen in $\beta 2 \mathrm{KO}$ in any of these features. The same pattern was found in layer $5 / 6$ of the visual cortex at P12, indicating that the deficits in glutamatergic synapses caused by $\alpha 7$ nAChR removal were not confined to the hippocampus (Fig. $1 E$ ).

To determine whether the deficits in glutamatergic synapses observed by imaging in $\alpha 7 \mathrm{KO}$ correlated with reductions in synaptic function, we quantified mEPSCs. TTX and gabazine were included to block action potentials and $\mathrm{GABA}_{\mathrm{A}}$ receptors, respectively. In acute hippocampal slices prepared at P12, mEPSC frequency in CA1 pyramidal neurons was significantly reduced in $\alpha 7 \mathrm{KO}$ compared with WTs (Fig. $2 A, B$ ). A similar decrement was seen in $\mathrm{dKO}$ s while $\beta 2 \mathrm{KO}$ s were indistinguishable from WTs. No change was seen in mEPSC amplitude in any of the KOs compared with WTs (Fig. $2 B$ ). Adding the nicotinic blockers $\mathrm{DH} \beta \mathrm{E}$ and MLA to WT slices to block $\beta 2^{\star}$-nAChRs and $\alpha 7$ nAChRs, respectively, $20 \mathrm{~min}$ before measuring mEPSC frequency did not alter the frequencies observed in WT neurons $(101 \pm 8 \%$ in MLA/DH $\beta$ E vs control). This eliminated the possibility that differences between WTs and KOs reflected endogenous acetylcholine acting through receptors in WTs to elevate mEPSC frequency acutely.

To determine whether the synaptic deficits persisted, we examined P25 animals. Immunostaining of the hippocampal CA1 again indicated a substantial deficit in glutamatergic synapses in $\alpha 7$ KOs compared with WTs (Fig. $2 C$ ). Patch-clamp recording also showed differences in mEPSC frequencies as found at P12: $\alpha 7 \mathrm{KOs}$ and dKOs both had lower mEPSC frequencies than did
A

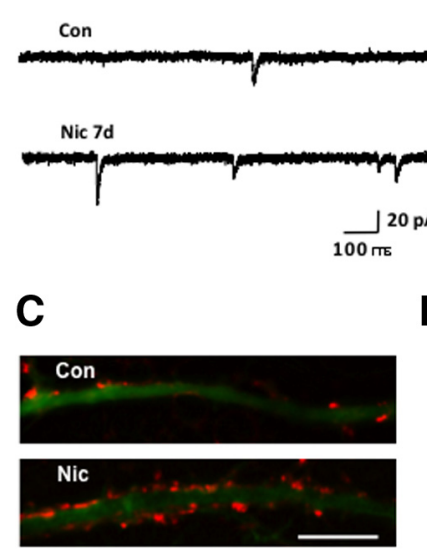

B
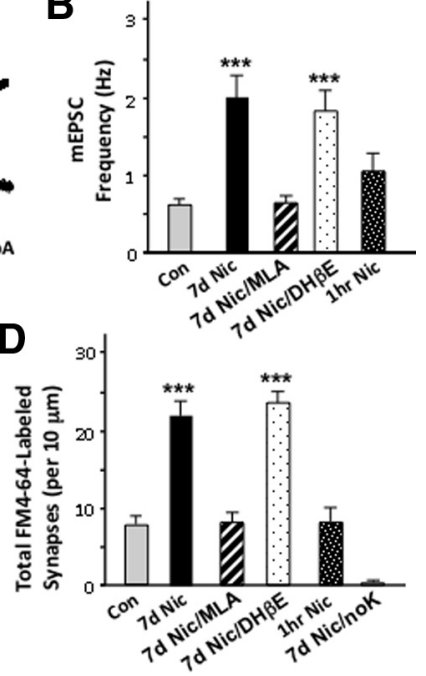

Figure 4. Nicotine-induced increases in the number of functional glutamatergic synapses in cell culture. Rat hippocampal cultures were incubated $7 \mathrm{~d}(7 \mathrm{~d}$ ) in nicotine (Nic) with or without blockers (MLA, DH $\beta \mathrm{E}$ ), rinsed to remove nicotine, and then incubated $1 \mathrm{~h}$ in MLA/DH $\beta \mathrm{E}$. As a control, some cultures received nicotine only during the last hour of the $7 \mathrm{~d}$ incubation (1 $\mathrm{h} \mathrm{Nic}$ ). $\boldsymbol{A}$, Patch-clamp recording of spontaneous mEPSCS in TTX and gabazine. $\boldsymbol{B}$, Quantification of mEPSC frequency (15-20 cells from 5-8 cultures per condition). $C$, Images of cells in culture having received the indicated treatment, then incubated with $\mathrm{MLA} / \mathrm{DH} \beta \mathrm{E}$ for $1 \mathrm{~h}$ followed by labeling with a 1 min incubation in FM4 - 64 (red) plus $50 \mathrm{~mm} \mathrm{KCl}$ to reveal active synapses on dendrites and spines of cells expressing GFP. Scale bar, $10 \mu \mathrm{m}$. D, Quantification of FM4 - 64labeled puncta. Baseline control (7d Nic/noK): $\mathrm{KCl}$ omitted from FM4 - 64 incubation ( $n=3-6$ cultures; 5-7 cells/culture).

WTs, $\beta 2 \mathrm{KOs}$ were equivalent to WTs, and none of the KOs differed from WTs in mEPSC amplitude (Fig. 2D). Immunostaining at times well into adulthood showed that the glutamatergic deficits persisted in $\alpha 7 \mathrm{KOs}$ : at P60 VGluT puncta $/ 400 \mu \mathrm{m}^{2}$ for WT versus $\alpha 7$ KOs were $83.3 \pm 1.7$ versus $58.1 \pm 2.6$ (mean values \pm SEM; $p<0.0001)$, respectively; for PSD-95, the values were $84.1 \pm 3.6$ versus $61.3 \pm 3.4(p<0.0001)$, and for colocalization $74.6 \pm 3.4$ versus $45.5 \pm 3.9(p<0.0001)$ in the CA1. The results support those from EM and immunostaining, indicating that the $\alpha 7-\mathrm{nAChR}$ gene product is required to establish normal numbers of glutamatergic synapses.

\section{Nicotine induction of functional glutamatergic synapses via $\alpha 7-$ nAChRs}

To determine whether nicotine can exploit $\alpha 7$-nAChR pathways to induce glutamatergic synapses and to gain additional evidence that $\alpha 7$-nACh-induced synapses are functional, we first turned to hippocampal cell culture. In the absence of septal input, hippocampal cultures have little, if any, endogenous cholinergic signaling (Lewis et al., 1967). Rat hippocampal cells in culture were incubated 1 week with $1 \mu \mathrm{M}$ nicotine, a concentration in the range of peak serum levels found in smokers (Matta et al., 2007); the cultures were then coimmunostained for GluR1-containing AMPA receptors and PSD-95. The nicotine treatment increased the numbers of GluR1 and PSD-95 puncta and their colocalization (Fig. $3 A, B$ ), suggesting increased numbers of synaptic contacts. Including either the $\alpha 7$-nAChR blocker MLA or $\alpha$ Bgt with the nicotine prevented the increases while the $\beta 2^{*}$-nAChR blocker $\mathrm{DH} \beta \mathrm{E}$ had no effect (Fig. $3 B$ ). This indicated that $\alpha 7$ nAChRS were needed for the induction. Similar results were obtained when the cultures were costained for VGluT and PSD-95, again yielding an increase in colocalization as expected for in- 
creased synaptic contacts (Fig. $3 C, D$ ). In contrast, immunostaining revealed no increase in the numbers of GAD-65 and $\mathrm{GABA}_{\mathrm{A}} \mathrm{R}$ puncta or in their colocalization, indicating that GABAergic synapses were unlikely to be changed in number by the nicotine treatment (Fig. 3E,F). The results strongly suggest that nicotine, acting through $\alpha 7$-nAChRs, increases the number of glutamatergic synapses in culture.

To determine whether the increased numbers of synaptic contacts represented functional synapses, we examined mEPSC frequency in TTX and gabazine at least an hour after replacing the nicotine with the blockers MLA and $\mathrm{DH} \beta \mathrm{E}$. A $7 \mathrm{~d}$ nicotine treatment substantially increased mEPSC frequency, and the effect was prevented by MLA but not by $\mathrm{DH} \beta \mathrm{E}$ (Fig. $4 A, B$ ); no change was seen in mEPSC amplitude (data not shown). Exposure to the same concentration of nicotine for only $1 \mathrm{~h}$ at the end of the $7 \mathrm{~d}$ period had no effect (Fig. $4 B$ ), thereby excluding the possibility that increased mEPSC frequency represented residual nicotine-activating receptors during the test itself. A similar outcome was obtained when functional synapses were identified by $\mathrm{KCl}$-stimulated uptake of the dye FM4-64 (Pyle et al., 1999). After replacing the nicotine with MLA/DH $\beta E$ for $1 \mathrm{~h}$, the cells were assayed for KCl-dependent FM4-64 uptake during a $1 \mathrm{~min}$ period (Fig. $4 C$ ). The nicotine treatment produced a significant increase in the number of FM4-64identified synapses (Fig. 4D). Including MLA with nicotine during the $7 \mathrm{~d}$ nicotine treatment completely blocked the increase, confirming that $\alpha 7$-nAChR activation was required. As seen above with mEPSC frequency, including $\mathrm{DH} \beta \mathrm{E}$ with the nicotine did not prevent the nicotineinduced elevation of FM4-64 uptake, indicating that $\beta 2^{\star}$-nAChR activation was not required. A $1 \mathrm{~h}$ nicotine exposure at the end of the $7 \mathrm{~d}$ period, as a negative control, produced no increase. The results indicate that nicotine, acting on $\alpha 7$-nAChRs, increases the number of functional glutamatergic synapses formed in cell culture.

To obtain additional evidence for the nicotinic effect, we examined mouse hippocampal slices in organotypic culture where ultrastructural analysis could be applied to the CA1 region. P4 slices were incubated $4-6 \mathrm{~d}$ with $1 \mu \mathrm{M}$ nicotine and then examined by EM. The nicotine treatment increased the number of synapses, and the increase was prevented by including MLA (Fig. $5 A, B)$. DH $\beta E$ had no effect. Evidence that the differences represented glutamatergic synapses came from immunostaining for either VGluT and PSD-95 or for GluR1 and PSD-95. Nicotine treatment increased puncta number in each case and increased colocalization of the respective pairs (Fig. 5C,D). MLA again blocked the effect, implicating $\alpha 7$-nAChRs, while $\mathrm{DH} \beta \mathrm{E}$ had no effect. The results indicate that extended nicotine exposure either in cell culture or in organotypic culture substantially increases the number of glutamatergic synapses formed and does so by activating $\alpha 7$-nAChRs. Nicotine in this way appears to mimic the effect of endogenous ACh on glutamatergic synapse formation in vivo.

\section{Cell-autonomous role for $\alpha 7$-nAChRs}

To determine whether the $\alpha 7-\mathrm{nAChR}$ requirement is cell autonomous, i.e., needed in the postsynaptic neuron, we used RNAi constructs to decrease $\alpha 7$-nACR expression acutely in vivo. These included constructs specific for $\alpha 7$-nAChRs ( $\alpha 7$-RNAi), for $\beta 2^{\star}$-nAChRs ( $\beta 2$-RNAi), and the corresponding scrambled sequences $(\alpha 7-\mathrm{Scr}, \beta 2-\mathrm{Scr})$ as controls. Mice were injected intracranially on P1-P2 with lentiviral constructs (Adesnik et al., 2008) containing the RNAi and were taken for immunostaining at P12. Two strategies were used to evaluate the relative numbers of glutamatergic synapses. In the first, regions were chosen in which heavy infection had occurred, causing most of the local neurons to express GFP. In these cases, the total numbers of VGluT, PSD-95, and colocalized puncta were counted in a 400 

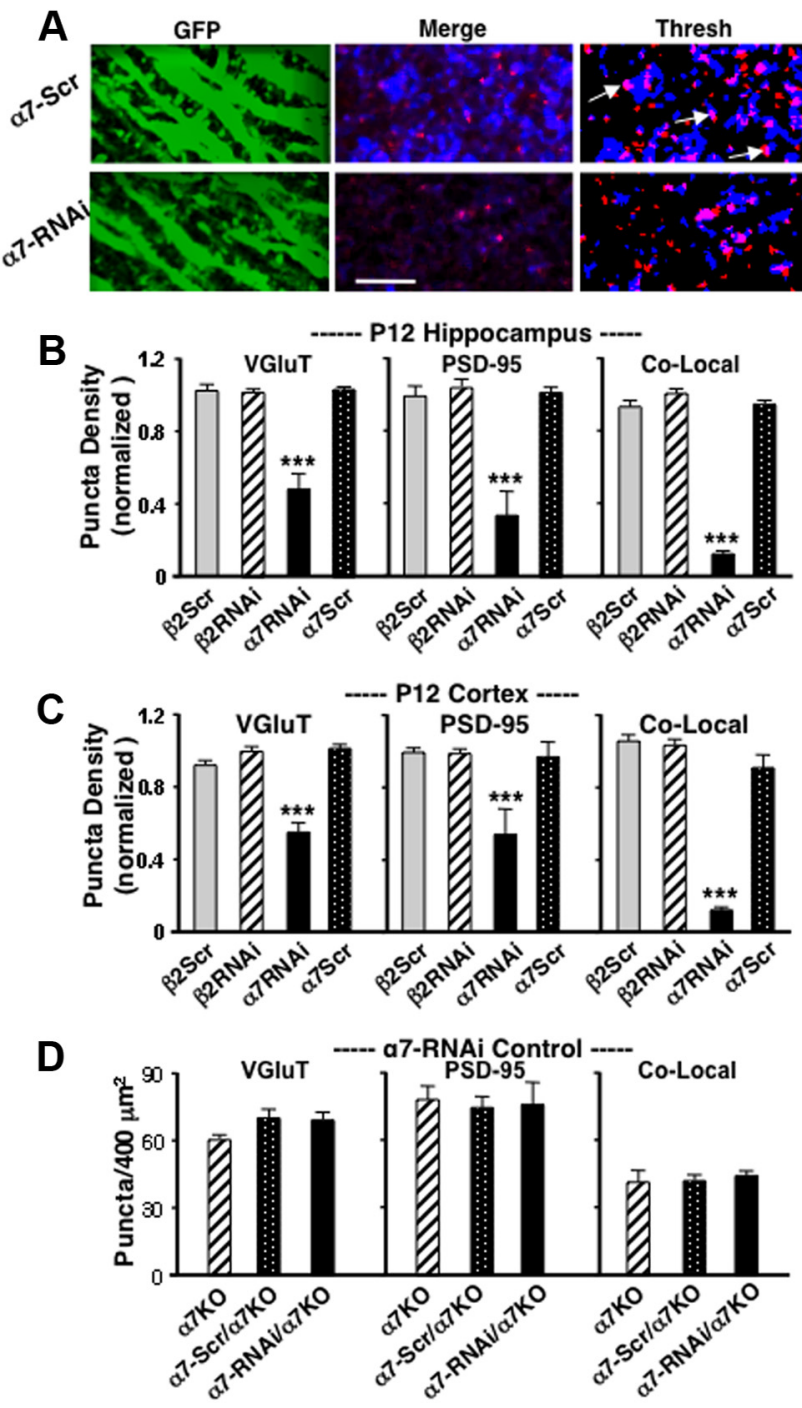

Figure 6. Relevance of local $\alpha 7$-nAChRs for glutamatergic synapse formation. A, Apical dendrite regions of $\mathrm{P} 12$ hippocampal CA1 expressing either lentiviral $\alpha 7$-Scr (upper) or $\alpha 7$ RNAi (lower) after intracranial injection in vivo (GFP) and immunostaining for VGluT (blue) and PSD-95 (red) shown together (Merge) and after thresholding (Thresh; arrows indicate examples of colocalization). Scale bar, $5 \mu \mathrm{m}$. B, Quantification of VGIuT, PSD-95, and colocalized puncta/ $400 \mu \mathrm{m}^{2}$ in P12 hippocampal CA1. C, Quantification in P12 visual cortex layer 5/6. Results are normalized to values obtained in adjacent regions lacking viral infection and demonstrate that $\alpha 7$-nAChRs within the local area are required for neurons to acquire WT levels of glutamatergic synapses. D, Quantification of VGluT, PSD-95, and colocalized puncta in $\alpha 7$ KOs expressing the indicated constructs, showing that the $\alpha 7$-RNAi construct has no off-target effects as defined by changes induced in $\alpha 7 \mathrm{KO}$ s (3 fields/animal; $4-8$ animals/condition).

$\mu \mathrm{m}^{2}$ area and compared with values obtained in a nearby control region lacking any detectable GFP. Normalizing the values to those obtained in adjacent control regions in this manner corrected for possible differences in staining among tissue sections. We found that expression of $\alpha 7$-RNAi in the hippocampal CA1 caused a significant reduction in the numbers of VGluT and PSD-95 puncta and a reduction in their colocalization, indicating fewer glutamatergic synapses (Fig. 6A,B). The adjacent uninfected control sites had consistent labeling across conditions for individual experiments, eliminating concerns about variation among sections (data not shown). Similar results were found in layer $5 / 6$ of the visual cortex where again $\alpha 7-\mathrm{RNAi}$, and only $\alpha 7$-RNAi, produced significant decrements (Fig. 6C). The $\alpha 7-$ RNAi displayed no off-target effects as assessed by expression in
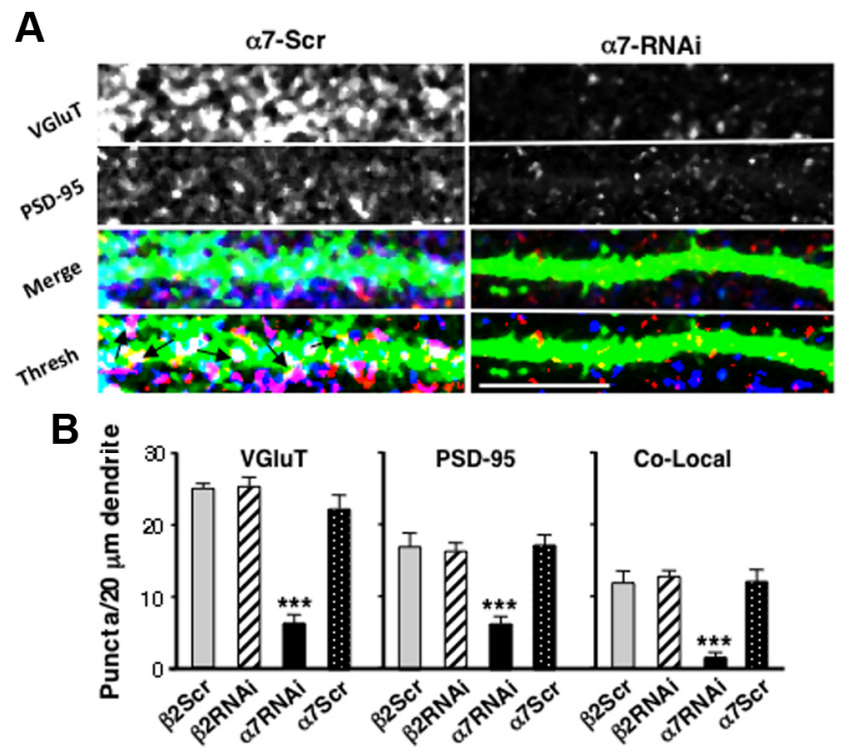

Figure 7. Cell-autonomous requirement for $\alpha 7$-nAChRs to promote glutamatergic synaptogenesis. $\boldsymbol{A}$, Isolated dendrites of P12 CA1 pyramidal neurons on the periphery of the virally infected area, expressing either $\alpha 7$-Scr (left) or $\alpha 7$-RNAi (right) and immunostained for VGluT (blue), PSD-95 (red), merged (Merge), and thresholded (Thresh). Arrows indicate examples of colocalized puncta. Scale bar, $10 \mu \mathrm{m}$. B, Quantification of puncta on isolated dendrites (from 3- 4 cells/animal, 4-8 animals/condition). Downregulation of the $\alpha 7-\mathrm{nAChR}$ gene product in isolated neurons reduces the number of glutamatergic synapses formed on the neuron, demonstrating a requirement for expression of the receptors by the postsynaptic cell for normal levels of glutamatergic innervation.

the cognate $\mathrm{KO}$ (Fig, $6 D$ ). Both the $\beta 2$-RNAi and $\alpha 7$-RNAi were effective in reducing their cognate receptor in cell culture (see Materials and Methods), and both have been used previously (Avale et al., 2008; Campbell et al., 2010).

As a second strategy to assess cell-autonomous actions of $\alpha 7$ nAChRs, we quantified puncta on individual isolated dendrites expressing the viral constructs on the perimeter of the infected region in the CA1. The same outcome was obtained: $\alpha 7$-RNAi prevented the neuron from receiving normal numbers of glutamatergic synapses, judging by the number of VGluT and PSD-95 puncta colocalized on the dendrite (Fig. $7 A, B$ ). The results demonstrate that neurons must express $\alpha 7$-nAChRs to acquire WT levels of glutamatergic synapses.

\section{Diminished ratio of glutamatergic/GABAergic input in $\alpha 7 \mathrm{KO}$ neurons}

The finding that nicotine increases the number of glutamatergic, but not GABAergic, synapses in culture raised the question of whether $\alpha 7$-nAChR deficits in vivo might generate a sustained imbalance of excitatory/inhibitory input to neurons. To examine this, we first used immunostaining to quantify GABAergic synapses in P12 $\alpha 7 \mathrm{KOs}$, as we had glutamatergic synapses. The presynaptic marker VGAT and the postsynaptic marker GABA $\alpha 1$ receptor were chosen for this purpose in hippocampal slices. No differences were found between WTs and either $\alpha 7 \mathrm{KOs}$ or $\beta 2 \mathrm{KOs}$ in the numbers or colocalization of the two kinds of puncta (Fig. $8 A, B$ ). Considering the reduced numbers of glutamatergic synapses, the results suggest that $\alpha 7 \mathrm{KO}$ neurons have a reduced ratio of glutamatergic/GABAergic contacts, compared with WTs and $\beta 2 \mathrm{KOs}$.

To test for functional differences in the ratio of excitatory/ inhibitory synaptic input to a neuron, we stimulated the Schaffer collaterals and adjacent regions while recording from CA1 pyra- 
midal neurons first at the reversal potential for GABA $(-70 \mathrm{mV})$ to quantify glutamatergic responses and then at the reversal potential for glutamate $(0 \mathrm{mV})$ to quantify GABAergic responses. The reversal potentials were established by using the recording electrode to dialyze the interior of the cell (Atallah and Scanziani, 2009). Gabazine blocked the response at 0 $\mathrm{mV}$, confirming it was GABAergic; APV and NBQX blocked the response at -70 $\mathrm{mV}$, confirming it was glutamatergic (data not shown). Comparing the evoked responses at 0 and $-70 \mathrm{mV}$ showed that $\alpha 7 \mathrm{KO}$ CA1 pyramidal neurons receive less glutamatergic transmission, normalized for GABAergic transmission, than do WTs (Fig. 8C,D). This difference remains at P25 (Fig. 8D).

The reduced glutamatergic input to $\alpha 7 \mathrm{KO}$ relative to $\mathrm{WT}$ neurons did not reflect an acute effect of $\alpha 7$-nAChRs on WT neurons during the recordings because repeating the stimulation in the presence of MLA did not alter the ratio of evoked responses in WT neurons (Fig. 8D, right; $1.45 \pm 0.14$ vs $1.41 \pm 0.12$ for EPSC(glutamatergic)/EPSC(GABAergic) in MLA vs control). Nor did the reduced glutamatergic input in $\alpha 7 \mathrm{KO}$ neurons appear to arise from differences in release probability at synapses onto the cells: comparing the peak amplitudes of two EPSCs evoked $100 \mathrm{~ms}$ apart yielded a paired-pulse ratio (PPR) that was equivalent in $\alpha 7 \mathrm{KO}$ and WTs (Fig. 8E,F). No change in PPR is generally interpreted as reflecting no change in release probably (Mao et al., 2011).Together, the results demonstrate a selective decrement in glutamatergic synapses on $\alpha 7 \mathrm{KO}$ neurons and a decrease in the amount of glutamatergic input compared with GABAergic input.

\section{Discussion}

Nicotinic cholinergic signaling occurs early in development throughout the nervous system (Zhang et al., 1998; Bansal et al., 2000; Adams et al., 2002; Hanson and Landmesser, 2003; Myers et al., 2005; Le Magueresse et al., 2006). The results presented here show that endogenous nicotinic signaling plays an unexpected and important role in shaping glutamatergic networks during development. Preventing expression of $\alpha 7-\mathrm{nAChRs}$ by neurons reduces the number of glutamatergic synapses they would otherwise receive. This dependence does not extend to GABAergic synapses, causing an imbalance: in the absence of $\alpha 7$-nAChRs, neurons receive a diminished ratio of functional glutamatergic/ GABAergic input. The sustained decrements seen in glutamatergic synapses and glutamatergic/GABAergic input to neurons represent important features of neural networks and likely account for a number of behavioral deficits found in mice lacking $\alpha 7$-nAChRs (Fernandes et al., 2006; Hoyle et al., 2006; Le Magueresse et al., 2006; Young et al., 2007; Levin et al., 2009).

The effects of $\alpha 7$-nAChRs on glutamatergic synapse formation are substantial. Ultrastructural analysis revealed a clear def-
B
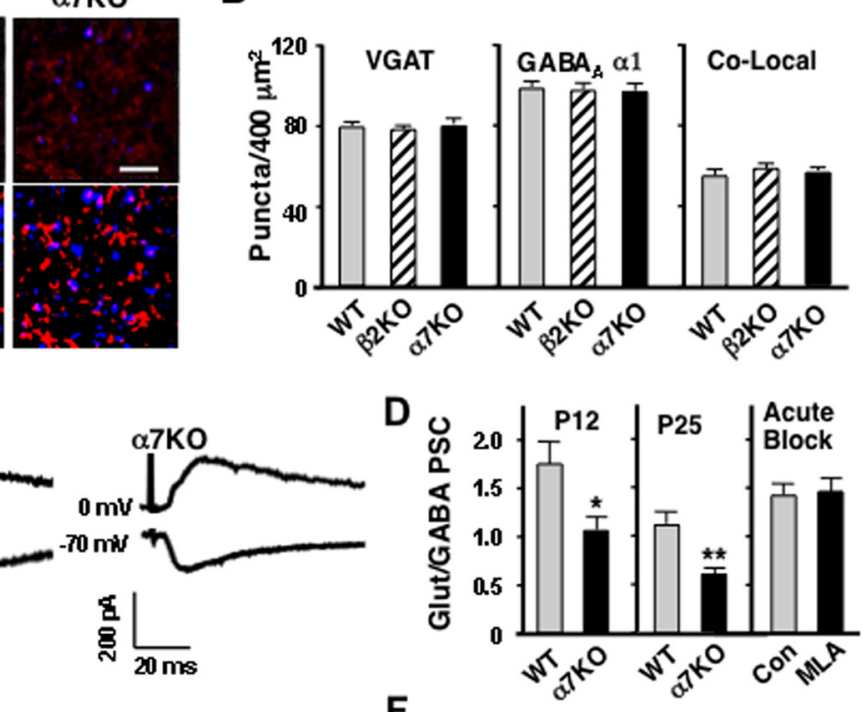

$\mathbf{F}$

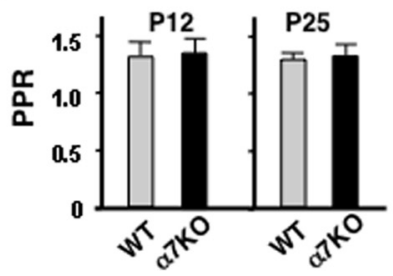

Figure 8. Decreased ratio of glutamatergic/GABAergic input in $\alpha 7 \mathrm{~K} 0$ neurons. $\boldsymbol{A}$, CA1 apical dendrite regions in P12 WT and $\alpha 7 K 0$ mice immunostained for VGAT (blue), GABA $\alpha 1$ receptor (red), merged (Merge), and thresholded (Thresh). Scale bar, 5

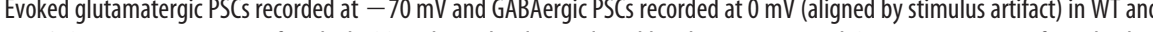
(Con) and after adding MLA (MLA), showing that the responses are not influenced by acute endogenous $\alpha 7-n A C h R$ signaling during the recordings ( 5 cells from 3 animals). $\boldsymbol{E}$, No differences were seen in PPR for evoked EPSCs amplitudes in $\alpha 7$ K0 versus WT twice, $100 \mathrm{~ms}$ apart (vertical line indicates stimulus artifact). $\boldsymbol{F}$, Ratio of the second EPSC amplitude divided by the first (PPR) for the indicated genotype at the indicated age (5-11 cells from 3-6 animals per genotype and age).

icit early on in total number of synapses in $\alpha 7 \mathrm{KO}$ compared with WTs. Immunostaining for presynaptic and postsynaptic markers expected at glutamatergic synapses indicated a pronounced deficit in the number of glutamatergic synapses in $\alpha 7 \mathrm{KO}$ s at all ages examined (P12-P60). No deficits were found in GABAergic synapses by immunostaining. Care was taken to compare across tissue samples at equivalent depths and exposure to antibody. Similar immunostaining criteria and quantification of colocalized puncta of presynaptic and postsynaptic markers have been widely used to quantify synapses (Christopherson et al., 2005; Kayser et al., 2006; Stevens et al., 2007; Eroglu et al., 2009).

The electrophysiological analysis also suggested that $\alpha 7 \mathrm{KO}$ have fewer glutamatergic synapses. Under conditions where GABAergic synapses were blocked, patch-clamp recording found reduced mEPSC frequency in $\alpha 7 \mathrm{KO}$ compared with WTs with no change in mEPSC mean amplitude. Moreover, the relative amplitude of evoked glutamatergic PSCs normalized for GABAergic PSCs in the same neuron was reduced in $\alpha 7 \mathrm{KOs}$ compared with WTs. No change was found in PPR under these conditions, arguing against a change in release probability. Though the mEPSC analysis alone would not exclude possible presynaptic changes, all of the data together-EM, immunostaining, and patch-clamp results-strongly support the conclusion that fewer functional glutamatergic synapses are found in $\alpha 7 \mathrm{KOs}$. 
Studies on hippocampal neurons in organotypic culture and in cell culture further corroborated the importance of $\alpha 7$ nAChRs. Nicotinic stimulation of the receptors increased the number of glutamatergic synapses formed on hippocampal neurons as assessed by immunostaining. This conclusion was further supported by the increases seen in mEPSC frequency and the increased number of puncta labeled by potassium-induced FM4-64 uptake. Ultrastructural analysis again confirmed an increase in total synapses, while immunostaining detected no changes in the number of GABAergic synapses. Control cultures largely, if not completely, lacked endogenous nicotinic cholinergic signaling; cholinergic input to the hippocampus is provided almost entirely by the septum (Lewis et al., 1967) which was not included in the cultures. As a result, blockade of $\alpha 7-n A C h R s$ with MLA during nicotine treatment consistently held glutamatergic synapse numbers at values seen in controls; MLA would not have been expected to reduce the values below those controls.

The nicotine experiments confirmed that $\alpha 7-n A C h R$ activation is likely essential for the beneficial effect of the receptors, rather than simply requiring their presence. Nicotine was used as an agonist to avoid activation of muscarinic receptors and to minimize degradation through hydrolysis. The concentration chosen was physiological in the sense that it represented the upper range found in heavy smokers. Notably nicotine exposure generated larger increases in the number of glutamatergic synapses than predicted from a comparison of WTs with $\alpha 7 \mathrm{KOs}$. This presumably reflects the chronic excessive stimulation of $\alpha 7$ nAChRs achieved in culture.

Deficits in dKOs were equivalent to $\alpha 7 \mathrm{KO}$ s whether quantifying total synapses by EM or glutamatergic synapses by immunostaining or mEPSC frequency by patch-clamp recording. No deficits were found in $\beta 2 \mathrm{KO}$ s by these criteria. Though adult $\beta 2 \mathrm{KOs}$ have altered patterns of dendritic spines (BallesteosYáñez et al., 2010) and unique behavioral deficits (Picciotto et al., 1995; Levin et al., 2009; Wang et al., 2009), absence of the $\beta 2$ $\mathrm{nAChR}$ gene does not appear to reduce the total number of glutamatergic synapses a neuron receives. While $\beta 2^{\star}$-nAChRs represent a major class of nicotinic receptors in the CNS, comparable in number to $\alpha 7$-nAChRs (Albuquerque et al., 2009; Gotti et al., 2009; Changeux, 2010), they do not appear to be required for glutamatergic synapse formation.

The fact that equivalent decrements in synapse number were found in the hippocampal CA1 and cortical layer 5/6 of $\alpha 7 \mathrm{KO}$ compared with WTs signals the breadth of the effect. It is distinct from the rapid action of presynaptic $\alpha 7-n A C h R s$ reported to activate "silent" glutamatergic synapses acutely in developing hippocampus (Maggi et al., 2003). In the present work, both immunostaining and EM revealed fewer synapses in $\alpha 7 \mathrm{KOs}$. Moreover, the RNAi knockdown experiments implicated $\alpha 7$ nAChRs on the postsynaptic neuron as being critical to achieve WT levels of glutamatergic synapses. Interestingly, $\alpha 7 \mathrm{RNAi}-$ induced deficits were substantially greater than those seen in $\alpha 7 \mathrm{KOs}$, perhaps reflecting a competitive disadvantage of the $\alpha 7$ RNAi-expressing neurons compared with "normal" neighbors. All neurons would have the same disadvantage in the $\alpha 7 \mathrm{KOs}$. It should be noted that the results do not exclude roles for other $\alpha 7$-nAChRs populations, perhaps on presynaptic terminals or even on adjacent astrocytes (McGehee et al., 1995; Fabian-Fine et al., 2001; Sharma and Vijayaraghavan, 2001; Le Magueresse et al., 2006), in supporting glutamate synapse formation or stabilization.

A likely mechanism for $\alpha 7$-nAChR effects on glutamatergic synapse formation is the ability of the receptors to elevate intra- cellular calcium. They do this via their permeability to calcium and by recruitment of calcium from other sources (Bertrand et al., 1993; Séguéla et al., 1993; Dajas-Bailador and Wonnacott, 2004; Fayuk and Yakel et al., 2007; Albuquerque et al., 2009; Shen and Yakel, 2009). Location and time course will shape outcome. Presynaptic $\alpha 7$-nAChRs enhance transmitter release by elevating local calcium (McGehee et al., 1995; Gray et al., 1996; Sharma and Vijayaraghavan, 2003). Postsynaptic $\alpha 7$-nAChRs can produce persistent changes by altering gene expression, presumably because of the signal transduction pathways available (Chang and Berg, 2001; Hu et al., 2002; Albuquerque et al., 2009). Altered gene expression is a plausible mechanism for enhancing synapse formation.

The ability of $\alpha 7$-nAChRs to increase glutamate synapse formation may also explain how this receptor helps determine when GABA converts from excitation to inhibition during normal early postnatal development. Previous work demonstrated that the conversion depends on activity through $\alpha 7$-nAChRs, accelerating the change in chloride transporters required to produce the mature chloride gradient that renders GABA inhibitory (Liu et al., 2006). Recent studies with adult-born neurons in the dentate gyrus demonstrate that the prolonged period of depolarizing GABAergic input found in $\alpha 7 \mathrm{KOs}$ correlates with reduced dendritic arborization and reduced glutamatergic input (Campbell et al., 2010). The extended period of GABAergic depolarization does not result in hyperinnervation. Instead, it most likely reflects a delay in development caused by the inability of synapse number in $\alpha 7 \mathrm{KOs}$ to reach some critical threshold required to drive the GABAergic conversion.

Endogenous nicotinic cholinergic control of glutamatergic synapse formation may help coordinate innervation across large neuronal populations in specific brain areas during development. Individual cholinergic neurons can have large innervation fields in the CNS (Witten et al., 2010), and the spontaneous waves of nicotinic excitation that occur at this time extend over large regions of the nervous system (Bansal et al., 2000; Hanson and Landmesser, 2003, 2006; Grubb et al., 2003; Myers et al., 2005; Le Magueresse et al., 2006). Neurons having the appropriate receptors and receiving cholinergic input could be recruited to a common network. Lack of required receptors or excessive stimulation by nicotine at early times could alter the pathways formed. Recent evidence indicates that endogenous nicotinic signaling retains the capacity to reorganize networks in the adult cortex if relieved of naturally occurring inhibition mediated by the endogenous prototoxin lynx1 (Morishita et al., 2010). The present work indicates that $\alpha 7$-nAChRs are likely to be key in this process, shaping network connectivity.

The deficits found here in $\alpha 7 \mathrm{KO}$ are substantial, and raise questions about how the animals function. A number of behavioral aberrations and cognitive deficits have been reported for $\alpha 7 \mathrm{KOs}$, including attention deficits, impaired spatial discrimination, and diminished working/episodic memory (Fernandes et al., 2006; Hoyle et al., 2006; Le Magueresse et al., 2006; Young et al., 2007; Levin et al., 2009). Many of these are likely to result directly or indirectly from the synaptic deficits reported here. Nonetheless, it is surprising that $\alpha 7$ KOs have not been found to display more extreme behavioral abnormalities, given their synaptic imbalances. One possibility is that the neural network develops compensatory mechanisms to use the existing connections more effectively; homeostatic mechanisms may come into play (Ibata et al., 2008; Turrigiano, 2008) to adjust for structural deficits in glutamatergic pathways. Another possibility, however, is that the rearing conditions and behavioral tests commonly 
used do not adequately reveal cognitive abilities intended for a more challenging environment. These will be interesting issues to pursue in the future.

\section{References}

CE, Broide RS, Chen Y, Winzer-Serhan UH, Henderson TA, Leslie FM, Freedman R (2002) Development of the $\alpha 7$ nicotinic cholinergic receptor in rat hippocampal formation. Dev Brain Res 139:175-187.

Adesnik H, Li G, During MJ, Pleasure SJ, Nicoll RA (2008) NMDA receptors inhibit synapse unsilencing during brain development. Proc Natl Acad Sci U S A 105:5597-5602.

Albuquerque EX, Pereira EFR, Alkondon M, Rogers SW (2009) Mammalian nicotinic acetylcholine receptors: from structure to function. Phys Revs 89:73-120.

Alkondon M, Albuquerque EX (2001) Nicotinic acetylcholine receptors $\alpha 7$ and $\alpha 4 \beta 2$ subtypes differentially control GABAergic input to CA1 neurons in rat hippocampus. J Neurophysiol 86:3043-3055.

Atallah BV, Scanziani M (2009) Instantaneous modulation of gamma oscillation frequency by balancing excitation with inhibition. Neuron 62:566-577.

Avale ME, Faure P, Pons S, Robledo P, Deltheil T, David DJ, Gardier AM, Maldonado R, Granon S, Changeux JP, Maskos U (2008) Interplay of $\beta 2^{\star}$ nicotinic receptors and dopamine pathways in the control of spontaneous locomotion. Proc Natl Acad Sci U S A 105:15991-15996.

Ballesteros-Yáñez I, Benavides-Piccione R, Bourgeois JP, Changeux JP, DeFelipe J (2010) Alterations of cortical pyramidal neurons in mice lacking high affinity nicotinic receptors. Proc Natl Acad Sci USA 107:11567-11572.

Bansal A, Singer JH, Hwang BJ, Xu W, Beaudet A, Feller MB (2000) Mice lacking specific nAChR subunits exhibit dramatically altered spontaneous activity patterns and reveal a limited role for retinal waves in forming ON/OFF circuits in the inner retina. J Neurosci 20:7672-7681.

Bertrand D, Galzi JL, Devillers-Thiéry A, Bertrand S, Changeux JP (1993) Mutations at two distinct sites within the channel domain M2 alter calcium permeability of neuronal alpha 7 nicotinic receptor. Proc Natl Acad Sci U S A 90:6971-6975.

Campbell NR, Fernandes CC, Halff AW, Berg DK (2010) Endogenous signaling through $\alpha 7$-containing nicotinic receptors promotes maturation and integration of adult-born neurons in the hippocampus. J Neurosci 30:8734-8744.

Chang KT, Berg DK (2001) Voltage-gated channels block nicotinic regulation of CREB phosphorylation and gene expression in neurons. Neuron 32:855-865.

Changeux JP (2010) Nicotine addiction and nicotinic receptors: lessons from genetically modified mice. Nat Rev Neurosci 11:389-401.

Christopherson KS, Ullian EM, Stokes CC, Mullowney CE, Hell JW, Agah A, Lawler J, Mosher DF, Bornstein P, Barres BA (2005) Thrombospondins are astrocyte-secreted proteins that promote CNS synaptogenesis. Cell 120:421-433.

Conroy WG, Nai Q, Ross B, Naughton G, Berg DK (2007) Postsynaptic neuroligin enhances presynaptic inputs at neuronal nicotinic synapses. Dev Biol 307:79-91.

Dajas-Bailador F, Wonnacott S (2004) Nicotinic acetylcholine receptors and the regulation of neuronal signalling. TIPS 25:317-324.

Dickinson JA, Kew JN, Wonnacott S (2008) Presynaptic alpha 7- and beta 2-containing nicotinic acetylcholine receptors modulate excitatory amino acid release from rat prefrontal cortex nerve terminals via distinct cellular mechanisms. Mol Pharmacol 74:348-359.

Eroglu C, Allen NJ, Susman MW, O’Rourke NA, Park CY, Ozkan E, Chakraborty C, Mulinyawe SB, Annis DS, Huberman AD, Green EM, Lawler J, Dolmetsch R, Garcia KC, Smith SJ, Luo ZD, Rosenthal A, Mosher DF, Barres BA (2009) Gabapentin receptor $\alpha 2 \delta$-1 is a neuronal thrombospondin receptor responsible for excitatory CNS synaptogenesis. Cell 139:380-392.

Fabian-Fine R, Skehel P, Errington ML, Davies HA, Sher E, Stewart MG, Fine A (2001) Ultrastructural distribution of the $\alpha 7$ nicotinic acetylcholine receptor subunit in rat hippocampus. J Neurosci 21:7993-8003.

Fayuk D, Yakel JL (2007) Dendritic Ca2 + signalling due to activation of alpha 7-containing nicotinic acetylcholine receptors in hippocampal neurons. J Physiol 582:597-611.

Fernandes C, Hoyle E, Dempster E, Schalkwyk LC, Collier DA (2006) Performance deficit of $\alpha 7$ nicotinic receptor knockout mice in a delayed matching-to-place task suggests mild impairment of working/episodiclike memory. Genes Brain Behav 5:433-440.

Fiala JC, Feinberg M, Popov V, Harris KM (1998) Synaptogenesis via dendritic filopodia in developing hippocampal area CAl. J Neurosci 18:8900-8911.

Freedman R, Leonard S, Olincy A, Kaufmann CA, Malaspina D, Cloninger CR, Svrakic D, Faraone SV, Tsuang MT (2001) Evidence for the multigenic inheritance of schizophrenia. Am J Med Genet 105:794-800.

Gotti C, Clementi F, Fornari A, Gaimarri A, Guiducci S, Manfredi I, Moretti M, Pedrazzi P, Pucci L, Zoli M (2009) Structural and functional diversity of native brain neuronal nicotinic receptors. Biochem Pharmacol 78:703-711

Grassi F, Palma E, Tonini R, Amici M, Ballivet M, Eusebi F (2003) Amyloid $\beta_{1-42}$ peptide alters the gating of human and mouse $\alpha$-bungarotoxinsensitive nicotinic receptors. J Physiol 547:147-157.

Gray R, Rajan AS, Radcliffe KA, Yakehiro M, Dani JA (1996) Hippocampal synaptic transmission enhanced by low concentrations of nicotine. Nature 383:713-716.

Grubb MS, Rossi FM, Changeux JP, Thompson ID (2003) Abnormal functional organization in the dorsal lateral geniculate nucleus of mice lacking the $\beta 2$ subunit of the nicotinic acetylcholine receptor. Neuron 40:1161-1172.

Gu Z, Yakel JL (2011) Timing-dependent septal cholinergic induction of dynamic hippocampal synaptic plasticity. Neuron 71:155-165.

Hanson MG, Landmesser LT (2003) Characterization of the circuits that generate spontaneous episodes of activity in the early embryonic mouse spinal cord. J Neurosci 23:587-600.

Hanson MG, Landmesser LT (2006) Increasing the frequency of spontaneous rhythmic activity disrupts pool-specific axon fasciculation and pathfinding of embryonic spinal motoneurons. J Neurosci 26:12769-12780.

Harrison PJ, Weinberger DR (2005) Schizophrenia genes, gene expression, and neuropathology: on the matter of their convergence. Mol Psychiatry 10:40-68.

Hennou S, Khalilov I, Diabira D, Ben-Ari Y, Gozlan H (2002) Early sequential formation of functional $\mathrm{GABA}_{\mathrm{A}}$ and glutamatergic synapses on $\mathrm{CA} 1$ interneurons of the rat foetal hippocampus. Eur J Neurosci 16:197-208.

Hoyle E, Genn RF, Fernandes C, Stolerman IP (2006) Impaired performance of alpha7 nicotinic receptor knockout mice in the five-choice serial reaction time task. Psychopharmacology (Berl) 189:211-223.

Hu M, Liu QS, Chang KT, Berg DK (2002) Nicotinic regulation of CREB activation in hippocampal neurons by glutamatergic and nonglutamatergic pathways. Mol Cell Neurosci 21:616-625.

Ibata K, Sun Q, Turrigiano GG (2008) Rapid synaptic scaling induced by changes in postsynaptic firing. Neuron 57:819-826.

Jacob MH, Berg DK (1983) The ultrastructural localization of $\alpha$-bungarotoxin binding sites in relation to synapses on chick ciliary ganglion neurons. J Neurosci 3:260-271.

Kayser MS, McClelland AC, Hughes EG, Dalva MB (2006) Intracellular and trans-synaptic regulation of glutamatergic synaptogenesis by EphB receptors. J Neurosci 26:12152-12164.

Le Magueresse C, Safiulina V, Changeux JP, Cherubini E (2006) Nicotinic modulation of network and synaptic transmission in the immature hippocampus investigated with genetically modified mice. J Physiol 576:533-546.

Levin ED, Petro A, Rezvani AH, Pollard N, Christopher NC, Strauss M, Avery J, Nicholson J, Rose JE (2009) Nicotinic $\alpha 7$ - or $\beta 2$-containing receptor knockout: Effects on radial-arm maze learning and long-term nicotine consumption in mice. Behav Brain Res 196:207-213.

Lewis PR, Shute CC, Silver A (1967) Confirmation from choline acetylase analyses of a massive cholinergic innervation to the rat hippocampus. J Physiol 191:215-224.

Liu Q, Kawai H, Berg DK (2001) $\beta$-Amyloid peptide blocks the response of $\alpha 7$-containing nicotinic receptors on hippocampal neurons. Proc Natl Acad Sci U S A 98:4734-4739.

Liu Z, Neff RA, Berg DK (2006) Sequential interplay of nicotinic and GABAergic signaling guides neuronal development. Science 314:1610-1613.

Maggi L, Le Magueresse C, Changeux JP, Cherubini E (2003) Nicotine activates immature "silent" connections in the developing hippocampus. Proc Natl Acad Sci U S A 100:2059-2064.

Mao D, Gallagher K, McGehee DS (2011) Nicotinic potentiation of excit- 
atory inputs to ventral tegmental area dopamine neurons. J Neurosci 31:6710-6720.

Matta SG, Balfour DJ, Benowitz NL, Boyd RT, Buccafusco JJ, Caggiula AR, Craig CR, Collins AC, Damaj MI, Donny EC, Gardiner PS, Grady SR, Heberlein U, Leonard SS, Levin ED, Lukas RJ, Markou A, Marks MJ, McCallum SE, Parameswaran N, et al. (2007) Guidelines on nicotine dose selection for in vivo research. Pyschopharmacology (Berl)190: 269-319.

McGehee DS, Heath MJ, Gelber S, Devay P, Role LW (1995) Nicotine enhancement of fast excitatory synaptic transmission in CNS by presynaptic receptors. Science 269:1692-1696.

Morishita H, Miwa JM, Heintz N, Hensch TK (2010) Lynxl, a cholinergic brake, limits plasticity in adult visual cortex. Science 330:1238-1240.

Myers CP, Lewcock JW, Hanson MG, Gosgnach S, Aimone JB, Gage FH, Lee KF, Landmesser LT, Pfaff SL (2005) Cholinergic input is required during embryonic development to mediate proper assembly of spinal locomotor circuits. Neuron 46:37-49.

Picciotto MR, Zoli M (2002) Nicotinic receptors in aging and dementia. J Neurobiol 53:641-655.

Picciotto MR, Zoli M, Léna C, Bessis A, Lallemand Y, Le Novère N, Vincent P, Pich EM, Brûlet P, Changeux JP (1995) Abnormal avoidance learning in mice lacking functional high-affinity nicotine receptor in the brain. Nature 374:65-67.

Pyle JL, Kavalali ET, Choi S, Tsien RW (1999) Visualization of synaptic activity in hippocampal slices with FM1-43 enabled by fluorescence quenching. Neuron 24:803-808.

Séguéla P, Wadiche J, Dineley-Miller K, Dani JA, Patrick JW (1993) Molecular cloning, functional properties, and distribution of rat brain alpha 7: a nicotinic cation channel highly permeable to calcium. J Neurosci 13:596-604.

Sharma G, Vijayaraghavan S (2001) Nicotinic cholinergic signaling in hippocampal astrocytes involves calcium-induced calcium release from intracellular stores. Proc Natl Acad Sci U S A 98:4148-4153.

Sharma G, Vijayaraghavan S (2003) Modulation of presynaptic store cal- cium induces release of glutamate and postsynaptic firing. Neuron 38:929-939.

Shen JX, Yakel JL (2009) Nicotinic acetylcholine-receptor mediated calcium signaling in the nervous system. Acta Pharmacol Sin 30:673-680.

Sheng M, Hoogenraad CC (2007) The postsynaptic architecture of excitatory synapses: a more quantitative view. Annu Rev Biochem 76:823-847.

Stevens B, Allen NJ, Vazquez LE, Howell GR, Christopherson KS, Nouri N, Micheva KD, Mehalow AK, Huberman AD, Stafford B, Sher A, Litke AM, Lambris JD, Smith SJ, John SW, Barres BA (2007) The classical complement cascade mediates CNS synapse elimination. Cell 131:1164-1178.

Stoppini L, Buchs PA, Muller D (1991) A simple method for organotypic cultures of nervous tissue. J Neurosci Methods 37:173-182.

Turrigiano GG (2008) The self-tuning neuron: synaptic scaling of excitatory synapses. Cell 135:422-435.

Wang L, Rangarajan KV, Lawhn-Heath CA, Sarnaik R, Wang BS, Liu X, Cang J (2009) Direction-specific disruption of subcortical visual behavior and receptor fields in mice lacking the $\beta 2$ subunit of nicotinic acetylcholine receptor. J Neurosci 29:12909-12918.

Witten IB, Lin SC, Brodsky M, Prakash R, Diester I, Anikeeva P, Gradinaru V, Ramakrishnan C, Deisseroth K (2010) Cholinergic interneurons control local circuit activity and cocaine conditioning. Science 330:16771681.

Young JW, Crawford N, Kelly JS, Kerr LE, Marston HM, Spratt C, Finlayson K, Sharkey (2007) Impaired attention is central to the cognitive deficits observed in alpha 7 deficient mice. Eur Neuropsychopharmacoll7:145-155.

Zhang J, Berg DK (2007) Reversible inhibition of $\mathrm{GABA}_{\mathrm{A}}$ receptors by $\alpha 7$ containing nicotinic receptors on the vertebrate postsynaptic neurons. J Physiol 579:753-763.

Zhang X, Liu C, Miao H, Gong ZH, Nordberg A (1998) Postnatal changes in nicotinic acetylcholine receptor $\alpha 2, \alpha 3, \alpha 4, \alpha 7$ and $\beta 2$ subunits genes expression in rat brain. Int J Dev Neurosci 16:507-518.

Zhong C, Du C, Hancock M, Mertz M, Talmage DA, Role LW (2008) Presynaptic type III neuregulin 1 is required for sustained enhancement of hippocampal transmission by nicotine and for axonal targeting of alpha7 nicotinic acetylcholine receptors. J Neurosci 28:9111-9116. 